\title{
Semi-Rigidity of Chain Trivalents as a Factor Contributing to their Adjacent Orientation at Metaphase I in Triploid Petunia
}

\author{
P. China Pullaiah, V. Padmaja and P.S.R.L. Narasinga Rao \\ Department of Botany, Andhra University, Waltair, India
}

Accepted October 4, 1991

To the extent studied by light microscopy indications are that in the present genotype of Petunia axillaris, chain trivalents may be unusual in three respects. One is that at metaphase I the frequency of linear configurations exceeds the frequency of alternate orientations when only chain trivalents are considered (China Pullaiah et al. 1991). Secondly, the frequency of adjacent orientation of chain trivalents may not be neglected; it seems a stable type in about $2 \%$ of the total trivalents analysed in PMC's at late metaphase-I this is far higher compared to pearl millet (Arundhati et al. 1986). Thirdly, in cells at prophase-I, semi-rigidity of unbranched chain trivalents is on occasion noted. The rigidity is in the form of what may be called a "hook-shaped" configuration of chain trivalent (compare bent chain trivalent in rye PMC'sSybenga and Rickards 1987). A pattern of semi-rigidity of multivalents is a point of theoretical significance in that chain trivalents in rye are nearly always alternate (Arundhati et al. 1986) on account of being bent at the centromere by the time of spindle formation. The somewhat non-plastic "hooks" here mentioned are the same as the ' $L$ ' shaped diakinesis chain trivalents described by Padmaja (1979), Reddi and Padmaja (1984), China Pullaiah (1988) and China Pullaiah et al. (1991) who noted that "hooks" are readily distinguished from '9' type trivalent of Darlington (1965; 'frying pan') and that in fact they are of the ' 7 ' type (Darlington 1965).

For convenience, we propose to describe the unusual bivalents and trivalents at diakinesis respectively as "paranormal rod bivalents" and "hook shaped chain trivalents". Neither type was at all in edivence in PMC's that passed the diakinesis stage. Thus the observation of a high frequency of linear forms of Petunia chain trivalents at metaphase-I on one hand and of hook shaped chain trivalents at diakinesis on the other hand would not seem causally related unless initiation of 'centromere activity' is, in some way, a diakinesis event. This issue is too remote to work out at present. Thus the present paper attempts to describe the unusual bivalents and hook shaped chain trivalents at pre-prometaphase I (Sybenga and Rickards 1987). This bears a relation to the idea that comparative lack of activity of the middle centromere vis a vis the end members reduces the probability of alternate orientation.

\section{Material and methods}

Through crosses between stabilized colchicine induced tetraploids and their diploid source population of Petunia axillaris (Lam.) B.S.P. four autotriploids $(2 n=3 x=21)$ were obtained. For meiotic study, young flower buds of 0.2 to $0.3 \mathrm{~mm}$ size were fixed in $1: 4$ acetic alcohol between 9.00 and 11.00 a.m. Smear preparations of PMC's were made in $1 \%$ acetocarmine and in alcoholic hydrochloric acid carmine (Snow's 1963). For the purpose of collecting quantitative data on orientation pattern, only the chain trivalent is taken into consideration. Observations are from intact cells as well as form cells showing thrown off trivalents. 


\section{Results}

Among the chain trivalents observed at diakinesis, some 'hook' type configurations or hooktype trivalents (Figs. 2,3) were observed. In the 'hooks' two chromosomes are apparently parallel to one another, possessing a chiasmate link in only one arm. The other arm of the middle chromosome formed a chiasma with one arm of the third chromosome. Thus, it would appear as if the first two chromosomes maintained contact at a single region distal to the centromere but yet lay nearly parallel to each other throughout their length. This type of hooks

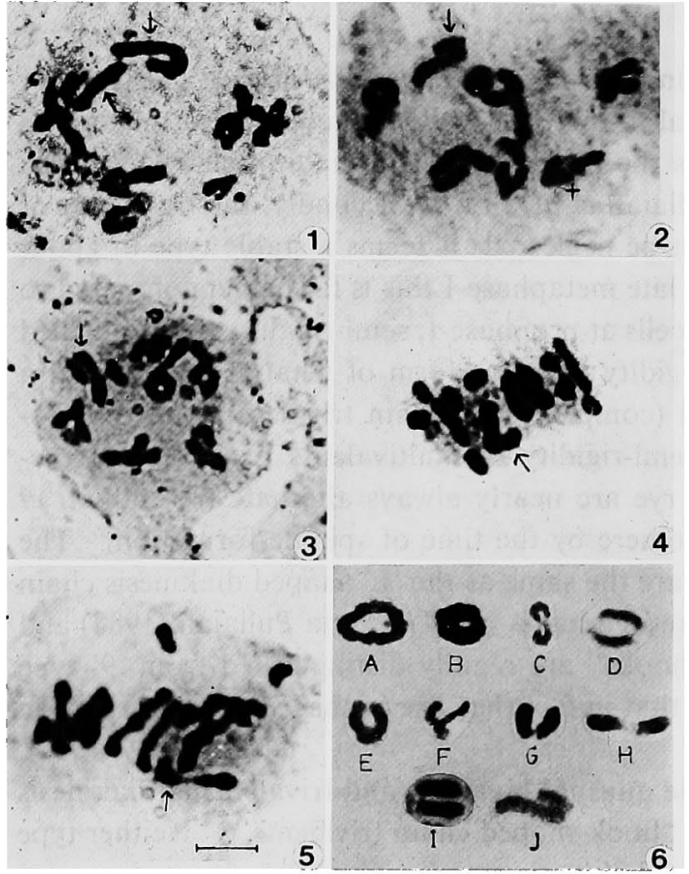

Figs. 1-6. Pollen mother cells of triploid Petunia axillaris (Lam.) B.S.P. showing chain trivalents. 1, PMC at diakinesis showing free curve chain trivalents $(\uparrow)$. 2, PMC at late diakinesis showing 'hook' shaped $(\uparrow)$ and free curve $(+)$ chain trivalents. 3, PMC at pro-metaphase I showing 'hook' shaped ( $\uparrow$ ) trivalent. 4 and 5, PMC at metaphase I showing adjacent orientation ( $\uparrow$ ) of chain trivalent. 6, Different types of ring bivalents (A-D) rod bivalents $(\mathrm{E}-\mathrm{H})$ paranormal bivalent $(\mathrm{I})$ and hook shaped trivalent $(J)$ at diakinesis (A to $I$ are bivalents; $\mathbf{J}$ is a trivalent). Scale represents $10 \mu \mathrm{m}$. accounted for 24.26 percent of the chain trivalents (Table 1). If they did influence orientation behaviour at metaphase $I$, it is reasonable to expect that reduced manoeuverability would decrease the proportion of alternate types and incidentally increase the proportion of adjacent types (Figs. 4, 5). That the proportion of adjacent chain trivalents is relatively high in this species has been previously noted (China Pullaiah et al. 1991).

\section{Discussion}

In unbranched 'linear' configurations of multivalents at late metaphase I, two of the centromeres which are not neighbours are sometimes seen poised disjuctionally with reference to each other (China pullaiah et al. 1991). Whether this is non-neighbour coorientation is a matter of definition (Sybenga and Rickards 1987). According to this workshop report, prevalence of such linear configurations in heteromorphic telo-trivalents and other trivalents in pearl millet (PMC's at M I) is probably related to the straightness of such trivalents at the diakinesis stage. Similar trivalents in 'rye' present a contrast (data of Sybenga in Arundathi et al. 1986). In diakinesis PMC's of rye, the unbranched trivalents are neither straight nor have they a free curvature. They are mostly rigid in the sense that they appeared bent at the centromere of the middle member of the trivalent. As a consequence, the middle centromere has a favourable "acceptance angle" for the interaction of the kinetochore microtubules with the spindle elements. One further consequence is that this centromere is always effective in MI/AI kinetics and generally disjoins both its neighbours. On the other hand in Petunia most chain trivalents were free curves at diakinesis and were not consistently straight and stiff (Figs. 1, 2). However, a significant proportion did show a bend-the bend was not at the centromere but at the sideward contact between two of the chromosomes. In all the 'bent' trivalents observed, the region of bending coincided with a chiasma which is nearly terminalized or is actually terminal 
(Figs. 2, 3). In such trivalents the same paired arms did not have a second chiasma. However, one of the two said chromosomes possessed one or two chaismata in the other arm involving a third chromosome. Such pre-metaphase I chain trivalents are described as 'hook' shaped trivalents and are distinct from both 'free curves' (Sybenga and Rickards 1987) and 'bent' trivalents (data of Sybenga in Arundhati et al. 1986).

If the hooks were due to one form of suspended or arrested "post-diplotene flaring-out of inter-chaismate bulges" (homologues in repulsion) or persistent affinity between the two homologues, then rod bivalents with comparable parallel arrangement of homologues should occur. Such a persistent, post-pairing, nonchaismate, parallel, alignment of members in a bivalent on one hand and a ' $\mathrm{V}$ ' shaped alignment in a rod bivalent on the other hand ought to be seen as a significant difference. However, in a descriptive sense, one might look upon this difference as a difference in degree (Figs. $6 \mathrm{~A}-\mathrm{D}, 6 \mathrm{E}-\mathrm{H}$ ) even if it were (in a process-sense) actually a difference in kind (Fig. 6 I versus E-H). In Fig. 6 I a chiasmate connection can be seen only to the left. To the right of the same bivalent blunt ends of the homologues are visible. The interest in the 'paranormal bivalent' (Fig. $6 \mathrm{I}$ ) with apparently parallel homogues at late diakinesis is that its existence bears a correspondence to the phenomenon of the 'hook' shape of some chain trivalents at diakinesis.

Table 1. Frequencies per cell (PMC at diakinesis) of different trivalent types and frequencies of sub-categories within the chain type trivalents

\begin{tabular}{|c|c|c|c|c|c|c|c|c|}
\hline \multirow{3}{*}{$\begin{array}{l}\text { Plant } \\
\text { No. }\end{array}$} & \multirow[b]{3}{*}{$\begin{array}{c}\text { Number } \\
\text { of } \\
\text { trivalents } \\
\text { (50 PMC } \\
\text { each) }\end{array}$} & \multirow[b]{3}{*}{$\begin{array}{c}\text { Per cell } \\
\text { trivalent } \\
\text { frequency }\end{array}$} & \multicolumn{6}{|c|}{ Number of chain trivalents } \\
\hline & & & \multirow{2}{*}{$\begin{array}{c}\text { No. of } \\
\text { C III } \\
\text { (hook type }+ \\
\text { free curve) }\end{array}$} & \multicolumn{3}{|c|}{ Hook type } & \multicolumn{2}{|c|}{ Free curve } \\
\hline & & & & Number & $\begin{array}{l}\text { Frequency } \\
\text { per cell }\end{array}$ & $\begin{array}{l}\text { Frequency } \\
\text { per chro- } \\
\text { mosome } \\
\text { set } \\
\text { (triplet) }\end{array}$ & Number & $\begin{array}{l}\text { Frequency } \\
\text { per cell }\end{array}$ \\
\hline $\mathrm{T}_{1}$ & 223 & 4.46 & 136 & $\begin{array}{c}21 \\
(15.44)\end{array}$ & 0.42 & 0.06 & $\begin{array}{c}115 \\
(84.50)\end{array}$ & 2.30 \\
\hline $\mathbf{T}_{12}$ & 208 & 4.16 & 132 & $\begin{array}{c}34 \\
(25.75)\end{array}$ & 0.68 & 0.09 & $\begin{array}{c}98 \\
(74.24)\end{array}$ & 1.96 \\
\hline $\mathrm{T}_{14}$ & 198 & 3.96 & 136 & $\begin{array}{c}40 \\
(29.41)\end{array}$ & 0.80 & 0.11 & $\begin{array}{c}96 \\
(70.58)\end{array}$ & 1.92 \\
\hline $\mathrm{T}_{24}$ & 226 & 4.52 & 136 & $\begin{array}{c}36 \\
(26.47)\end{array}$ & 0.72 & 0.10 & $\begin{array}{c}100 \\
(73.52)\end{array}$ & 2.00 \\
\hline
\end{tabular}

Numbers in parenthesis indicate percentages (C III)

If the forces responsible for the appearance of paranormal rod bivalents are the same that give rise to 'hook' type trivalents, then the effect of this rigidity in the trivalent is of some interest. Compared to the centromere of the free member of the trivalent, and that of the other end member, the centromere of the middle member has a disadvantageous 'acceptance angle' between the centric-and spindle-elements. It could thus have a less than one-third chance to be the first centromere to engage the spindle components. In other words, compared to the two end members it could be the 'slowest' in development such that it could become 'nonsyntelic' or ineffective or inactive.

A chain trivalent with such a middle centromere could assume "a linear configuration" at metaphase I. However, if the said mid centromere does become syntelic (even when late), it may not disjoin both its neighbours, which are by then already syntelic. When it disjoins only one neighbour the configuration could be stabilized as an adjacent orientation at metaphase I. Calculated as per triplet frequency of semi-rigidity the abnormality had a value of 0.09 but its frequency per chromosome-pair was much lesser being 0.01 . Thus the assumed 
correspondence between the conditions leading to 'paranormal bivalents' and the conditions leading to 'hook-type trivalents' needs to be fully explored. However, the unusual conditions may apply more to some sets of homologues than to others, and could prove difficult to study in small samples. One other feature was that the low fequency of paranormal bivalents did seem to correlate with the frequency of spontaneous aneuploidy observed in the progenies of selfed disomics. Furthermore, the paranomals and hooks may be treated as aberrants which "provide us with the opportunity to examine variations on the meiotic theme" as pointed out by Ashley (1987).

\section{Summary}

In pollen mother cells of triploid Petunia axillaris (Lam.) B.S.P. at the stage of late diakinesis some of the chain trivalents revealed an unusual form of rigidity. These are here described as "hook-shaped", although earlier documented as ' $L$ ' shaped chain trivalents (Reddi and Padmaja 1979). The other point considered was whether a similar form of rigidity is also true for some rod bivalents, where the single chiasma was terminalized. Such "paranormal bivalents" were in fact observed. The corresponding observation of hook-shaped trivalents at late diakinesis is interpreted to be a factor that could limit the frequency of alternate orientation and incidentally increase the frequency of adjacent orientation of such chains at metaphase I.

\section{Acknowledgements}

One of us (PCP) is grateful to the University Grants Commission for the award of a fellowship in S.A.P.

\section{References}

Arundhati, A., Narasinga Rao. P. S. R. L. and Sybenga, J. 1986. Possible causes of variation in trivalent orientation in pearl millet and rye. Genetica 70: 81-87.

Ashley, T. 1987. Meiotic behavior of sex chromosomes: What is normal ? Chromosomes Today 9: 184-195.

China Pullaiah, P. 1988. Studies on chromosome associations and their orientation in autotriploids of Petunia. M. Phil. dissertation submitted to the Andhra University, Waltair.

-, Narasinga Rao. P.S. R. L. and Padmaja V. 1991. Prevalence of linear configuration among chain trivalents at metaphase I in Pollen Mother Cells of Petunia axillaris (LAM.) B. S. P. Cytologia 56: 367371 .

Darlington, C. D. 1965. Recent advances in Cytology. J. and A Churchill Ltd., London (3rd edition).

Padmaja, V. 1979. Cytogenetics of induced mutants and polyploids in Petunia. Ph. D. thesis, Andhra University, Waltair (India).

Reddi, V. R. and Padmaja, V. 1984. Chromosome behaviour in triploid Petunia. J. Indian Bot. Soc. 63: 124128.

Richard, Snow. 1963. Alcoholic hydrochloric acid-carmine as a stain for chromosomes in squash preparations. Stain Technology $38: 9-13$.

Sybenga, J. and Rickards, G. K. 1987. The orientation of multivalents at meiotic meatphase I: a Workshop Report. Genome 29: 612-620. 